\title{
Molecular Mechanisms of Acute Brain Injury and Ensuing Neurodegeneration
}

\author{
Francisco J. Ortega, Jose M. Vidal-Taboada, \\ Nicole Mahy and Manuel J. Rodríguez \\ Unitat de Bioquímica i Biologia Molecular, Facultat de Medicina, \\ Institut d'Investigacions Biomèdiques August Pi i Sunyer (IDIBAPS), \\ Universitat de Barcelona and Centro de Investigación Biomédica en Red sobre \\ Enfermedades Neurodegenerativas (CIBERNED), Barcelona \\ Spain
}

\section{Introduction}

Injury to the central nervous system (CNS), including stroke, traumatic brain injury and spinal cord injury, cause devastating and irreversible damage and loss of function. For example, stroke affects very large patient populations, results in major suffering for the patients and their relatives, and involves a significant cost to society. CNS damage implies disruption of the intricate internal circuits involved in cognition, the sensory-motor functions, and other important functions. There are currently no treatments available to properly restore such lost functions. New therapeutic proposals will emerge from an understanding of the interdependence of molecular and cellular responses to CNS injury, in particular the inhibitory mechanisms that block regeneration and those that enhance neuronal plasticity.

In this chapter we explore the hypothesis that different CNS insults induce similar molecular and cellular processes that lead to neuronal death and the ensuing neurodegeneration. Thus, acute CNS injury is characterized by immediate, massive neuronal death and marked tissue injury that arise from interdependent mechanisms such as glutamate-mediated excitotoxicity, failure of energy production, acidosis, generation of reactive oxygen species (ROS), and a potent inflammatory reaction. Acute brain injury can also activate a neurodegenerative process whose effects are time-dependent and related to the initial severity of the primary insult. In addition to misfolded protein aggregation, the same common molecular and cellular processes, including chronic excitotoxicity, calcium homeostasis dysregulation, energy failure and chronic inflammation, underlie the pathology of neurodegenerative diseases.

\section{Acute CNS disorders have common molecular mechanisms}

Acute CNS injury is characterized by immediate, massive neuronal death and marked tissue injury as a result of uncontrolled local necrosis. This primary injury expands in the surrounding tissue for weeks through interdependent mechanisms such as glutamate 
receptor over-stimulation, failure of cellular energetics, acidosis, the generation of ROS, and a potent inflammatory response, all of which further cell death and tissue destruction (Figure 1).
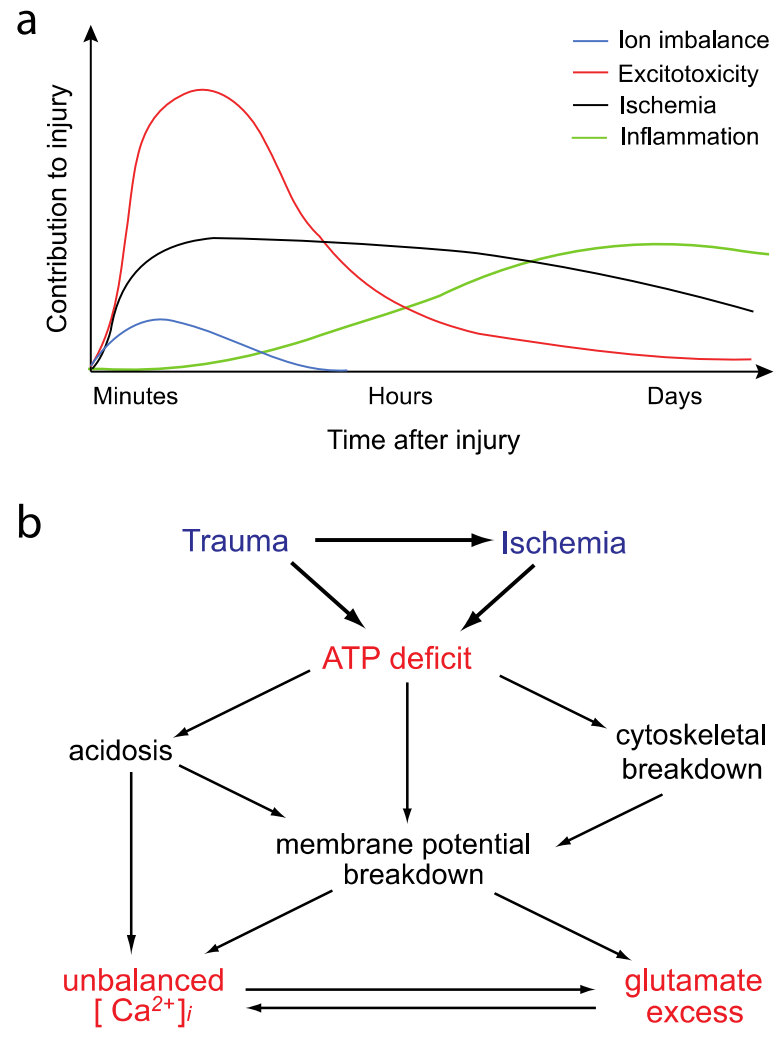

Fig. 1. Pathophysiology of traumatic brain injury and ischemia. a) Kinetics of the main events taking place in the lesioned CNS after an acute injury. b) ATP availability, intracellular calcium and extracellular glutamate determine the cascade of the interdependent molecular processes leading to neuronal death

\subsection{Molecular mechanisms of excitotoxicity after acute CNS injury}

Glutamate accounts for most of the excitatory synaptic activity in the CNS through three groups of receptors: two ionotropic receptors (N-Methyl-D-aspartate (NMDA) and a-amino-3hydroxy-5-methyl-4-isoxazole propionic acid (AMPA)-kainate receptors); and one group of metabotropic receptors, which are coupled to G proteins. Although non-NMDA receptors are not initially permeable to calcium, glutamate release in the synaptic cleft increases postsynaptic and glial membrane permeability, which leads to a transient increase in intracellular calcium concentration $\left(\left[\mathrm{Ca}^{2+}\right]_{\mathrm{i}}\right)$ (Obrenovitch et al., 2000). Excessive activation of glutamate receptors can directly trigger neuronal death through a process characterized by chronic glutamate release and the consequent $\left[\mathrm{Ca}^{2+}\right]_{\mathrm{i}}$ dys-homeostasis in neurons and astrocytes (Lau 
\& Tymianski, 2010) with the formation of intracellular calcium precipitates (Rodríguez et al., 2001). This process, defined as excitotoxicity, also involves cellular influxes of $\mathrm{Na}^{+}$and $\mathrm{Cl}^{-}$and efflux of $\mathrm{K}^{+}$, and the resulting cell swelling (Chen et al., 1998, Katayama et al., 1995).

The link between excitotoxicity, excessive $\left[\mathrm{Ca}^{2+}\right]_{i}$ increase, and neuronal death (Figure 1) has been established from data obtained from neuronal cultures and rodent models of hypoxiaischemia and of cerebral lesions (Lau \& Tymianski, 2010, Verkhratsky, 2007). In these studies, the induced neuronal death can be blocked with intracellular calcium chelators (Tymianski et al., 1993) or voltage-operated calcium channel antagonists, extracellular calcium removal, or emptying of the cellular calcium stores (Verkhratsky, 2007). In addition, an increase in $\left[\mathrm{Ca}^{2+}\right]_{i}$ plays a direct role in the neuronal damage observed during cerebral ischemia and epileptic seizures (Verkhratsky, 2007).

Therefore, control of the cellular calcium homeostasis is a key element in ensuring an adequate cellular response at any moment. When intracellular calcium movements overload this homeostatic balance, the extrusion systems are activated and $\mathrm{Ca}^{2+} / \mathrm{Na}^{+}$antiporters and mitochondrial $\mathrm{Ca}^{2+}$ uniporter lead to a reduction in intracytosolic calcium (Lau \& Tymianski, 2010). Once the first wave is stopped, calcium-binding proteins release calcium, which is extruded by the highly efficient plasma membrane calcium ATPases (Verkhratsky, 2007). A similar process takes place in mitochondria, in the nuclear envelope, the endoplasmicreticulum network, and the secretory vesicles. All of these systems have a critical dependence on energy availability and the interplay between them decreases the cytoplasmatic calcium levels in a coordinated way (Beck et al., 2004). Any alteration of the cellular energy metabolism will alter calcium homeostasis and vice versa (Berridge, 1998).

The mechanisms by which calcium exerts its toxic actions remain controversial. It has been proposed that an increase in $\left[\mathrm{Ca}^{2+}\right]_{i}$ may over-stimulate cellular processes that normally operate at low levels, or it may trigger certain cascades that are not usually functional (Tymianski \& Tator, 1996). Some of the mechanisms directly activated by calcium or $\mathrm{Ca}^{2+}$ calmodulin include energy depletion due to a loss of mitochondrial membrane potential, the production of ROS, membrane gap formation through an over-activation of phospholipase A2, calpain-induced cytoskeleton breakdown, and endonuclease mediated DNA degradation (Nicholls et al., 2003, Verkhratsky, 2007). Also, excessive calcium induces peroxidation of phospholipids and a release of arachidonic acid, which is metabolized to proinflammatory eicosanoids.

In addition to causing calcium dys-homeostasis, excitotoxicity also induces acidosis inside the cells and in the extracellular space. There are several mechanisms by which $\mathrm{pH}$ decreases with neuronal injury. Mitochondrial damage forces the cell to a shift from aerobic to anaerobic metabolism and as a result the glucose is oxidized to lactate with the formation of only two ATPs and the release of two protons (Chan et al., 2006). After trauma and ischemia, extracellular lactate increases dramatically and the $\mathrm{pH}$ decreases. To ensure neuronal viability during human hypoxia, oxygen is reserved for neurons and astroglial glycogen is oxidized to lactate, which is rapidly transported into neurons for its complete oxidation, to satisfy the high energy demand and prevent further damage (Sibson et al., 1998). Protons also appear during some chemical reactions such as phospholipid hydrolysis. In parallel, calcium influx causes a rapid cytoplasmic acidification (Werth \& Thayer, 1994) through the membrane $\mathrm{Na}^{+} / \mathrm{H}^{+}$exchanger that restores the $\mathrm{Na}^{+}$gradient and the $\mathrm{Ca}^{2+}$ dependent displacement of protons bound to cytoplasmic anions (Tymianski \& Tator, 1996). 
Although the mechanisms by which acidosis produces neuronal damage remain unclear, some hypotheses have been proposed. Protons may reduce $\mathrm{K}^{+}$conductance and thus facilitate action potentials. Moreover, reinforced by energetic depletion, a $\mathrm{pH}$ decrease inhibits the $\mathrm{Na}^{+} / \mathrm{Ca}^{2+}$ exchange, thereby contributing to the breakdown of membrane potential and increasing the $\left[\mathrm{Ca}^{2+}\right]_{i}$ again. Acidosis may also inhibit neurotransmitter reuptake, enhance free radical production and accelerate DNA damage (Tymianski \& Tator, 1996). However, a $\mathrm{pH}$ decrease also helps prevent further neuronal damage by NMDA receptor blockade and $\mathrm{Ca}^{2+}$ influx reduction into the cell (Kaku et al., 1993).

As a consequence of the excessive $\left[\mathrm{Ca}^{2+}\right]_{i}$ and acidosis nucleation of calcium phosphate crystals (i.e. hydroxyapatite crystals) frequently occurs in the cytoplasm of injured neurons and astrocytes, leading to a process of tissue calcification. Cellular microcalcification has been observed in a variety of human pathologies, such as vascular dementia, Alzheimer's disease (AD), Parkinson's disease (PD), astrogliomas, and posttraumatic epilepsy, and also develops in rodent excitotoxic models of CNS injury in a common pattern. (Ramonet et al., 2006, Rodríguez et al., 2001). Excitotoxic paradigms in rat CNS lead to intracellular calcium precipitation similar to brain calcification in humans (Ramonet et al., 2002, 2006). These experiments demonstrate that calcium deposit formation does not depend on the glutamate receptor subtype initially stimulated, but rather on the cell type involved. Although the significance of cell calcification is unknown, some findings point to calcium precipitation as a mechanism to overcome excitotoxicity. The homogeneous morphology of these deposits in CNS areas and pathologies suggests common synaptic processes (Ramonet et al., 2006), where variability depends on cellular type (astrocyte or neuron), glutamatergic activity, and energy availability. Thus, hydroxyapatite formation brings about a reduction in free calcium ions with no energy expenditure, which may constitute an alternative homeostatic step in reducing excitotoxicity after CNS damage. (Ramonet et al., 2006, Rodriguez et al., 2000)

\subsection{Energy availability determines cell survival or death}

Ultimately, acute brain damage can be viewed as an energy crisis that results from either an impaired energy production, as in ischemia or hypoglycemia, or pathologically elevated energy demands, as in a sustained seizure (Sapolsky, 2001). Early energy depletion leads to ischemic cell death. Within a few minutes, the membrane potential is lost and thus the neuronal and glial cells become depolarized. This activates the presynaptic, voltagedependent calcium channels and results in the release of excitatory amino acids into the extracellular space, thereby inducing further neuronal calcium overload, release of intracellular ROS and depletion of glutathione (Orrenius et al., 2003). This primary injury then expands through an excitotoxic spiral, which involves ever-increasing mitochondrial dysfunction, an increase in $\left[\mathrm{Ca}^{2+}\right]_{i}$, the release of glutamate, membrane depolarization, ROS production, acidosis, and NMDA receptor desensitization (Figure 2). If the homeostatic threshold is exceeded, the activation of proteases would further accelerates this cycle, which finally results in excitotoxic cell death (Mattson, 2006, Orrenius et al., 2003).

Neuronal demise resulting from excitotoxicity was classically believed to lack the regulated series of events involved in a death program and was therefore considered to be invariably necrotic. However, key regulators of apoptosis, such as p53, Bcl-2 and caspases, are also involved in excitotoxicity and ischemic CNS injury, and a wide continuous spectrum of situations between apoptosis and necrosis has finally been redefined (Nicotera et al., 1999). 

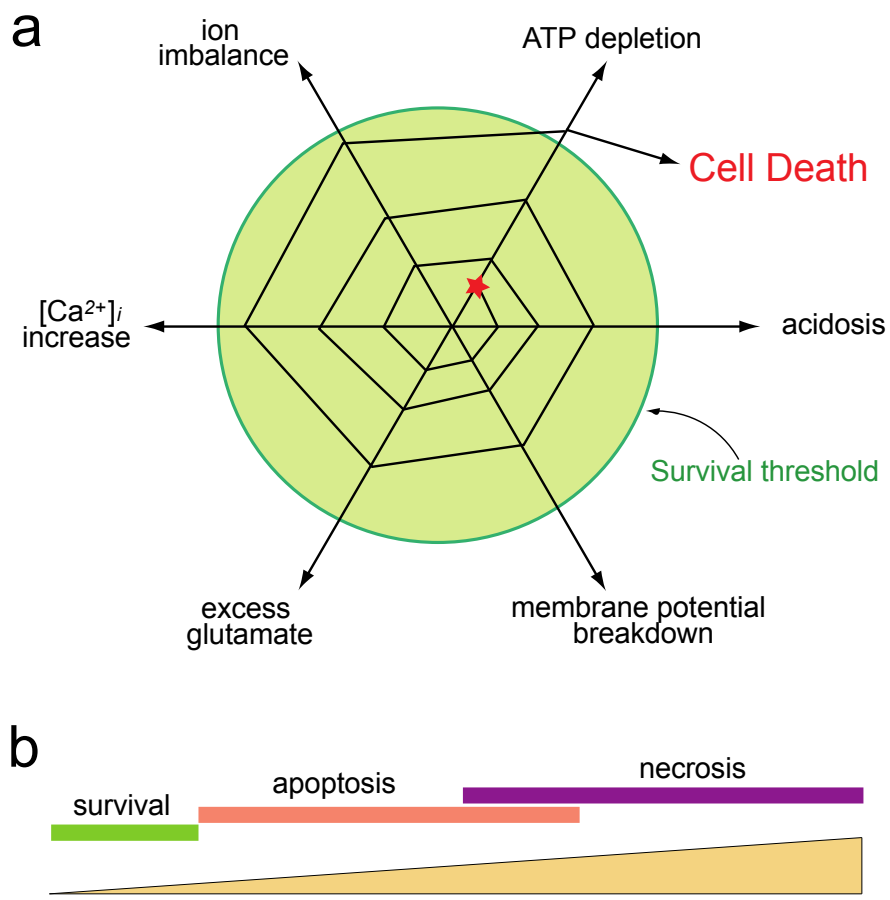

Intensity of injury

Fig. 2. Accelerating loops of excitotoxicity and cell death. a) An initial insult causes a limited disturbance of cellular homeostasis; the starting point (red star) being for example the ATP depletion due to a discrete localized hypoxia. Looping mechanisms cause an ever increasing mitochondrial dysfunction and acidosis, an increase in $\left[\mathrm{Ca}^{2+}\right]_{\mathrm{i}}$ and in glutamate release, with membrane depolarization and ion imbalance. Beyond a certain threshold, the activation of cell death program would further accelerate the cycles leading to neuronal death. b) Under mild injury, the initial aggression would be compensated by cellular defense mechanisms; with a more severe damage, neurons would die by apoptosis, necrosis or a mixed program (adapted from Nicotera et al., 1999).

After a stroke, collateral vessels maintain sufficient blood flow to allow the potential survival of cells in areas adjacent to the core of the infarct. Cells in this penumbra area have impaired function but remain viable for a period of time (Vosler et al., 2009). In the area where oxygen depletion is only moderate, cells can activate their own apoptotic program, which requires ATP to be executed. The mitochondria play a role in either necrotic or apoptotic cell death, depending on the severity of the initial insult (Beal, 2000). Apoptosis is favored after mild insults when ATP production of the cell is relatively well preserved, whereas necrosis occurs in response to a severe insult, such as severe ischemia. Cells then die rapidly due to cell swelling, activation of proteases, and cell membrane breakdown. Thus, for each cell type, the factors that determine the pattern of cell death at any moment are the intensity of the lesion, the $\left[\mathrm{Ca}^{2+}\right]_{\mathrm{i}}$ and the cellular energy production. The cell then 
prevents the uncontrolled release of intracellular compounds (e.g. glutamate) and the subsequent inflammatory response of tissue. As ATP decreases, the necrotic process starts presenting a hybrid pattern involving both cell death types (Figure 2).

\subsection{Neuroinflammation as a retaliatory mechanism against CNS damage}

Inflammatory cells participate in tissue remodeling after CNS injury. Microglia, which are generally considered the immune cells of the CNS, normally monitor the brain environment and respond to the functional state of synapses by sensing and eliminating defunct synapses (Wake et al., 2009), controlling synaptogenesis (Bessis et al., 2007) and clearing newborn adult hippocampal neuroprogenitors (Sierra et al., 2010). After CNS injury, microglia become reactive, adopt an amoeboid shape and upregulate a variety of surface molecules and the release of cytokines. In addition, marked recruitment, proliferation and activation of microglial cell precursors from the blood can be detected in damaged regions of the brain (Soulet \& Rivest, 2008), and when the blood brain barrier (BBB) integrity has been compromised by the insult, a variety of inflammatory cells, such as activated leukocytes, rapidly penetrate the brain (Frijns \& Kappelle, 2002). These inflammatory cells have a dual role in the early and late stages of stroke. For instance, regardless of the cellular origin, MMP-9 is initially detrimental but promotes brain regeneration and neurovascular remodeling in the later repair phase (Amantea et al., 2009), and therefore may be involved in further brain damage or repair.

In addition to microglia, astrocytes and endothelial cells are also involved in the intracerebral immune response to CNS injury. All of these cell types act, in part, by secreting cytokines, chemokines, neurotrophic or neurotoxic factors (Bailey et al., 2006). For example, activated microglial cells migrate towards dying neurons in response to neuroinflammation and can exacerbate local cell damage (Streit, 2005). Microglia also respond to interferon $(\mathrm{IFN})_{Y}$ and tumor necrosis factor (TNF)- $\alpha$ by expressing class I and II major histocompatibility complex molecules (MHC-I and -II, respectively) as well as costimulatory molecules, which allows them to function as antigen-presenting cells (Kettenmann et al., 2011). Astrocytes that also express MHC molecules, but lack costimulatory molecules, can present antigen to primed memory $\mathrm{T}$ cells but not to naive $\mathrm{T}$ cells (Neumann et al., 1996). Furthermore, astrocytes respond by releasing other complement proteins and acute-phase proteins, such as a1-antichymotrypsin and a2-macroglobulin, as well as neuronal growth factors and cytokines (Kettenmann et al., 2011). As a hallmark, microglia are normally the first cells in the brain to react to acute injury and recruit astrocytes by secreting acute-phase proteins, particularly those belonging to the complement system, and also by releasing cytokines, such as interleukin (IL)-1 $\beta$ and TNF- $\alpha$, and ROS species (Kettenmann et al., 2011). Unlike their role in phagocytosis, activated microglia are classified as antigen-presenting cells, as they upregulate MHC-II, and under certain conditions following brain inflammation or injury, activated microglia aid in brain repair, providing a potent neuroprotection (Carson et al., 2006) or acting as a proneurogenic influence that supports the different steps of neurogenesis (Ekdahl et al., 2009).

Microglia do not constitute a unique cell population, but rather, show a range of phenotypes (Schwartz et al., 2006) that are closely related to the evolution of the lesion process (Graeber \& Streit, 2010). In a dynamic equilibrium with the lesion microenvironment, these phenotypes range from the well-known proinflammatory activation state (classically 
activated or M1) to a neurotrophic one that is involved in cell repair and extracellular matrix remodeling (alternatively activated or M2) (Dirscherl et al., 2010). Thus, microglia differentiate into cells that exacerbate tissue injury or promote CNS repair when they receive signals from the close surroundings. M1 microglia/macrophages, activated via tolllike receptors and IFN $\gamma$, produce proinflammatory cytokines and oxidative metabolites that facilitate their role as indiscriminate killers of infectious agents and tumor cells (Mantovani et al., 2004), with collateral damage to healthy cells and tissue. Conversely, M2 microglia/macrophages form in the presence of IL-4 or IL-13, downregulate inflammation, and facilitate wound healing, with the induction of scavenger receptors and matrixdegrading enzymes that enhance phagocytosis and promote tissue repair, i.e., by promoting angiogenesis and matrix remodeling (Mantovani et al., 2004, Sica et al., 2006). Furthermore, the crosstalk between elements of the neuroinflammatory response and those that interact with neural stem cells might activate endogenous neurogenesis and facilitate brain repair (Rolls et al., 2007).

\section{Acute brain injury can trigger neurodegeneration}

Acute brain injury can also activate a neurodegenerative process whose effects are timedependent and related to the initial severity of insult. For example, acute neurological injury and chronic brain damage have been linked in boxers, with a correlation between the prevalence of subdural hematoma and dementia pugilistica (Miele et al., 2006). Also, cerebrovascular diseases and processes initiated by ischemia reperfusion may be central in the pathogenesis of AD (Zlokovic, 2005), including abnormal protein aggregation processes.

Neurodegenerative disorders are characterized by distinct clinical features that result from a discrete progressive neuronal loss, leading to specific structural alterations in the brain and various forms of cerebral dysfunction over periods of years. However, common molecular and cellular processes, such as excitotoxicity, $\left[\mathrm{Ca}^{2+}\right]_{i}$ increase, energy failure and chronic inflammation may also underlie different neurodegenerative diseases (Lau \& Tymianski, 2010). In these situations, as described for acute CNS injury, a link between the over-activation of excitatory amino acid receptors, an increase in $\left[\mathrm{Ca}^{2+}\right]_{i}$, energy failure, and neuronal death has also been established (Bano et al., 2005, Randall \& Thayer, 1992).

\subsection{Chronic excitotoxicity as part of neurodegenerative processes}

Glutamate excitotoxicity has been inextricably linked to ischemic CNS injury and secondary injuries that occur following traumatic brain injury, whereas the chronic glutamate-mediated over-excitation of neurons is a newer concept that has linked excitotoxicity to neurodegenerative processes in amyotrophic lateral sclerosis (ALS), Huntington's disease, AD and PD (Lau \& Tymianski, 2010). Such a chronic excitotoxic process can be triggered by a dysfunction of glutamate synapses, due to an anomaly at the pre-synaptic, post-synaptic, or astroglial level (Rodriguez et al., 2009b). For example, loss of ionotropic receptor selectivity and deficiencies in glial glutamate re-uptake are present in ALS (Obrenovitch et al., 2000). These dysfunctions also help to explain phenomena such as the aging-related hypoactivity of NMDA receptors observed in AD (Olney et al., 1997) and the AMPA-receptor increase detected in the hippocampus of aged-impaired rats (Le Jeune et al., 1996). 
The contribution of excitotoxicity to the neurodegenerative process can be reproduced by the microinjection of low doses of glutamate agonist into the rodent brain. Due to the high affinity of ionotropic glutamate receptors for their specific agonists, NMDA, AMPA or kainate injected in non-saturable conditions can trigger calcium-mediated excitotoxicity in several rat brain areas and induce an ongoing neurodegenerative process (Bernal et al., 2000, Petegnief et al., 2004, Rodriguez et al., 2000, Rodriguez et al., 2004). For example, any microinjection of glutamate agonist in the rat medial septum triggers a persistent process that leads to a progressive septal atrophy with a cholinergic and GABAergic neuronal loss and a concomitant neuroinflammation that does not parallel the lesion (Rodriguez et al., 2009a). These paradigms also mimic the alterations of other neurotransmitter systems and neuromodulators found in human neurodegeneration. Thus, long-term ibotenic-induced lesion in the rat basal forebrain leads to a loss of cholinergic afferents and decreased extracellular noradrenaline, glutamate, and taurine. At a functional level, excitotoxic disruption of the septohippocampal pathway also consistently reproduces some of $\mathrm{AD}$ memory impairments (Waite et al., 1994).

CNS damage caused by an acute injury directly depends on the initial severity and the time elapsed after injury. But each variable activates different mechanisms. Comparison of the rat medial septum response to the insult caused by graded concentrations of AMPA with the time-course effects of a low dose of AMPA showed evidence of marked differences in the lesion dynamism (Rodriguez et al., 2009a). Thus, the medium dose of AMPA increased calcification and the degree of microglia reaction in the GABAergic region of the septal area, whereas atrophy and neuronal loss only reached a plateau with the higher AMPA doses. Results of a six-month study with a low AMPA-dose evidenced a progressive increase in neuronal death and septal atrophy with astrogliosis and microgliosis during the first month, and a total absence of calcium precipitates. Septal damage does not then increase with the intensity of an excitotoxic insult, but rather it progresses with time, meaning different mechanisms are involved in each situation.

\subsection{Uncoupling of retaliatory systems and energy availability}

Given the toxic effects of glutamate-mediated over-stimulation, adaptations that act to decrease synaptic accumulation of glutamate have the potential to be protective. Within these protective mechanisms, some are conducted to inhibit glutamate release during insults and some others involve retrograde signaling of inhibitory neurotransmitters and neuromodulators. Thus, the release of GABA, taurine and adenosine presents a retaliatory activity that has shown neuroprotective properties during glutamate-mediated neuronal insults (see Sapolsky, 2001 for a review). All of the processes mediated by these neuromodulators are interdependent and the coordination between the effects of GABA, taurine and adenosine helps avoid excessive synaptic glutamate and control neuronal damage.

Control of synaptic glutamate levels, when not coupled to energy production, renders neurons susceptible to death. Under controlled conditions, the stoichiometric coupling of glutamatergic activity and glucose metabolism accounts for $80 \%$ of total cerebral glucose (Sibson et al., 1998). Part of this energy is needed for glutamate recycling in a coordinated process involving astrocytes and neurons, with $15 \%$ of brain oxidative metabolism contributed by astroglia (Lebon et al., 2002). A reduction in energy availability and the 
consequent altered glutamate activity may then play a role in apoptotic or necrotic neuronal death (Ramonet et al., 2004).

However, the balance between retaliatory system actions and energy metabolism can be disrupted by glutamate-mediated neuronal injury and then play a role in the evoked neurodegenerative process. For example, AMPA microinjection in the medial septum induces a progressive neuronal loss associated with a long-term decline of the hippocampal functions and decreased GABAergic and glutamatergic activities (Rodriguez et al., 2005). By contrast, this same hippocampal lesion increases adenosine and taurine transmissions, glutamate recycling and glucose metabolism (Ramonet et al., 2004, Rodriguez et al., 2005). Over time, adenosine replaces GABA in the control of glutamate neurotransmission to avoid further excitotoxic damage when cholinergic and GABAergic processes are compromised. This same lesion paradigm induces apoptotic neuronal loss in the hippocampus with enhancement of neuronal glycolysis and a glutamate/glutamine cycle displacement towards glutamine production that decreases glutamate concentration (Ramonet et al., 2004). In addition, glutamine is removed from the synapses, probably through vessels, where it inhibits NO synthesis, exhibiting a clear vasodilatory effect. In this scenario, the hippocampal increase in neuronal energy metabolism, which is associated with a decreased glutamate neurotransmission and neuronal apoptotic death, reflects a neurodegenerative process with unfulfilled coordination of the retaliatory systems and a chronic energy requirement to execute the apoptotic program.

\subsection{Neurodegeneration results from dysregulation of calcium homeostasis}

As mentioned above, the over-activation of glutamate receptors results in a massive increase in the cytoplasm calcium levels, which requires considerable energy expenditure to restore $\left[\mathrm{Ca}^{2+}\right]_{\mathrm{i}}$ to its physiological basal level. Dysregulation of calcium homeostasis alters the rapid and coherent activation of neurons and is therefore ultimately responsible for many common aspects of brain dysfunction in neurodegenerative diseases. For example, calciummediated apoptosis may underlie the etiology of chronic neurodegenerative disorders such as $\mathrm{AD}$ and PD.

In $\mathrm{AD}$ pathogenesis, multiple cellular and molecular alterations involve alterations in synaptic calcium handling and perturbed cellular calcium homeostasis. With ageing neurons encounter increased oxidative stress and impaired energy metabolism, which compromise the control of membrane excitability and $\left[\mathrm{Ca}^{2+}\right]_{\mathrm{i}}$ dynamics (Camandola \& Mattson, 2011). Also in AD, elevated intracellular calcium levels contribute to the enhanced amyloidogenic processing of the amyloid-beta precursor protein (APP) (Liang et al., 2010) and mediates its cytotoxic effects. The cytotoxic actions of amyloid beta (A $\beta$ ) involve calcium as a central mediator of pathological actions through two mechanisms. First, when aggregating at the cell surface $A \beta$ generates ROS, which results in membrane lipid peroxidation (Mark et al., 1997) that ultimately impairs glucose and glutamate transporters thereby promoting excitotoxicity (Keller et al., 1997, Mark et al., 1997). As a second mechanism, $A \beta$ oligomers may form calcium-permeable pores in the plasma membrane. Also, glutamate receptor-mediated calcium elevations cause changes in tau protein similar to those seen in neurofibrillary tangles (Mattson, 1990). Other studies report that preseniline- 1 mutations perturb calcium dynamics at the glutamatergic and 
cholinergic synapses, suggesting a pivotal role for aberrant neuronal calcium regulation in AD.

Since alterations in calcium homeostasis have also been reported in other neurodegenerative disorders associated with an accumulation of misfolded protein aggregates, including PD, Huntington's disease, ALS, and transmissible spongiform encephalopathies (TSEs) (Camandola \& Mattson, 2011), these alterations are considered a common pathophysiological factor linked to neuronal degeneration. Thus, neurodegenerative diseases that exhibit diverse clinical and neuropathological phenotypes share the common features of glutamate-mediated over-excitation and calcium dyshomeostasis. Together with misfolded protein aggregation, these features participate in the pathogenic process that progressively reduces cell function and survival within the nervous system, leading to neurological disability and often death. Therefore, the different CNS aggressions of genetic, infectious, environmental or other origins can induce the same neurodegenerative injury. This convergence is due to the multi-directional interactions between the neurons, glial cells, extracellular matrix, endothelia and host immune cells that regulate tissue homeostasis and orchestrate the tissue response to the insult.

\subsection{Molecular mechanisms of misfolded protein aggregation}

Nearly all neurodegenerative disorders, such as AD, PD, Huntington's disease, TSEs, Tauopathies, ALS, and frontotemporal lobar degeneration with ubiquitin-positive inclusions, share common neuropathology (Forman et al., 2004). Thus, since they primarily feature the presence of abnormal protein inclusions containing specific misfolded proteins, these disorders are also classified as misfolded protein diseases (MPD). Some of these misfolding proteins are polyglutamine, protease-resistant prion protein, $A \beta$, Tau, $a-$ synuclein, SOD1, TDP-43 or FUS, and share no common sequence or structural identity (Morales et al., 2010; Soto et al., 2006). Protein aggregation defines neurodegenerative diseases broadly, but with significant differences between the affected areas of CNS and the damaged neuronal type. For example, cholinergic neurons are preferentially affected in AD, dopaminergic neurons in PD, and motor neurons in ALS.

Correct folding requires proteins to assume one particular structure and failure to adopt its proper structure is a major threat to cell function and viability. Consequently, elaborated systems have evolved to protect cells from misfolded proteins, including the molecular chaperones that promote proper protein folding and the ubiquitin-proteasome system that degrades the newly translated proteins that failed to fold correctly (Gitler \& Shorter 2011). In this system, the misfolded protein accumulation often reflects the cellular response to an imbalanced protein homeostasis, and relates to a perturbation of cellular function and aging. As mentioned above, all of the protective systems need abundant concomitant cellular energy production, and the frequent hypoxic or hypoglycemic incidents associated with hypercholesterolemia, diabetes and hypertension reduce energy availability and participate in the pathogenesis of neurodegenerative diseases (Forman et al., 2004, Haces et al., 2010). Consequently, these misfolded proteins develop insidiously in patients over their lifetime, and manifest clinically until middle or late life, as a MPD.

The common pathogenic mechanism of MPD represents the initial aggregation and CNS deposition of one type of misfolded protein in the nucleus or cytosol of specific neurons 
and/or well-located extracellular space (Gadad et al., 2011). In fact, the amyloid formation follows a crystallization-like process, known as seeding-nucleation, which, through a slow interaction between misfolded protein monomers, initially forms an oligomeric nucleus, or seed, around which a second, faster phase of elongation takes place. The nuclei formation is a slow process and represents the limiting step, and the extent of amyloidosis depends on the number of seeds produced (Carulla et al., 2010). In time, the progressive aggregation of fibrillar structures, with short stretches of $\beta$-pleated sheet stabilized by intermolecular interactions and oriented perpendicular to the fibril axis, leads to abundant extended insoluble amyloidogenic proteins, with deleterious effects (Sanchez et al., 2011). The formation of different oligomeric aggregates also occurs, and the exposure of their hydrophobic amino acid residues on their external surface changes their solubility and interactions with their cellular targets. For example, in $\mathrm{AD}$, a soluble $4 \mathrm{kDa}$ peptide is initially produced and the amyloidogenic $A \beta$, which is identified as the main component of $\mathrm{AD}$ oligomers and senile plaques, readily interacts with other $\mathrm{A} \beta$ molecules to progressively form a wide range of oligomers and soluble aggregates (Carulla et al., 2005). This continued amyloidogenesis gives rise to the high molecular weight and insoluble amyloid fibrils that are highly abundant in senile plaques. A $\beta$ plays a recurring role in protein phosphorylation, signal transduction mechanisms, cytoskeletal organization, multiprotein complex formation, and synaptotoxicity, and when analyzing its pathogenic aggregation, the oligomers present the higher neurotoxicity.

All A $\beta$ aggregation states and actions are also influenced by the abnormal activity of transition metal ions. Trapped in fibrils, they completely alter their structure, are electrochemically active, and can generate ROS in the presence of hydrogen peroxide and reducing agents. The biometal age-related dyshomeostasis causes a variation of their activity, especially in metalloproteins like SOD1 or the prion protein. In fact, the variety of binding affinities and binding sites reported for copper to $A \beta$, $\alpha$-synuclein, SOD1 and the prion protein indicate that, through these numerous possible interactions, the copper level may directly drive the diversity of the states and functions of these proteins (Drew et al., 2010).

TSEs are considered unique among MPD in that they are transmissible; besides many amyloid pathological aggregates also have the ability to do so, and epidemiological data show that they are not infectious. However, several intriguing experimental results argue for a general infectious principle in protein misfolding and aggregation diseases in the pioneering studies of Westermark (1985) and Higuchi (1983), on systemic amyloidosis associated with the deposition of Amyloid-A and apolipoprotein AII. In PD, the infectious protein would be SNCA, whose abnormal conversion of native from to $\beta$-sheet is triggered or supported by various drivers, such as hereditary factors, aging, oxidative stress, or environmental toxins (Taylor et al., 2002). Nevertheless, disease propagation by different protein infectious agents remains to be proven in most neurodegenerative diseases.

\subsection{Amyloid beta deposition after acute brain injury}

$\mathrm{A} \beta$ is a physiological peptide that has a constant turnover in the brain (Saido \& Iwata, 2006), and the potential causes for its deposition is the determinant of three main factors: 1) increased expression of APP, 2) aberrant enzymatic cleavage of APP by $\beta$ - and $\gamma$-secretase, 
and 3) disruption of $A \beta$ clearance from the CNS through the BBB. Therefore, rats subjected to chronic hypoperfusion or cerebral ischemia (Koistinaho \& Koistinaho, 2005, Pluta, 2004) may show transient up-regulation and accumulation of APP and A $\beta$ in the cortex boundary and white matter with decreased blood flow, which suggests an interplay between cerebrovascular and amyloid pathology. Therefore, stroke and hypoperfusion are important risk factors for amyloidosis (De La Torre, 2008). In this regard, studies of brain imaging in humans (Johnson et al., 2005, Rombouts \& Scheltens, 2005), and animal models of cerebral hypoperfusion and of impaired clearance of $A \beta$ across the BBB by the receptor for advanced glycation end products (RAGE) (Deane et al., 2004), denote that cerebrovascular dysfunction may precede cognitive decline and the onset of neurodegenerative changes in AD (Drzezga et al., 2003). Both increased and impaired brain-to-blood transport of A $\beta$ across the BBB have been observed in AD (Deane et al., 2003). In AD patients, and particularly after ischemia (Fukuda et al., 2004), matrix metalloproteinase machinery is also overexpressed in the cerebral vessels, which can degrade basement membranes and extracellular matrix proteins, and subsequently compromise the BBB integrity. As reviewed in detail elsewhere (Saido \& Iwata, 2006), endothelial cells can also directly degrade A $\beta$-expressing enzymes such as insulin-degrading enzyme and neprilysin. Therefore, if the integrity of the endothelium is compromised by all of these mechanisms, an imbalance of the degradation and clearance of $A \beta$ should be expected.

In addition to the RAGE, low-density lipoprotein receptor related protein 1 is expressed in the vascular-CNS barrier, and both are critical for the regulation of $A \beta$ receptors at the $B B B$. Their impaired activity may also contribute to the $A \beta$ accumulation resulting in neuroinflammation, disconnection between the cerebral blood flow and metabolism, altered synaptic transmission, neuronal injury, and amyloid deposition into parenchymal and neurovascular lesions (Deane et al., 2004), therefore both receptors are critical for regulation of $A \beta$ homeostasis in the CNS. Indeed, $A \beta$-RAGE suppression of cerebral blood flow is mediated by endothelial cells secretion of Endothelin-1 (Deane et al., 2003), leading to hypoperfusion and negatively affecting the synthesis of proteins required for memory and learning, and eventually causing neuritic injury and neuronal death.

Axonal injury is one of the most common and important pathological features of brain trauma and ischemia. In these situations, APP is a marker of axonal injury and accumulates due to the disruption of fast anterograde axonal transport (Smith et al., 2003). In particular, lysis of the terminal swollen bulb of disconnected axons may serve as a vehicle for the release of potentially toxic proteins, peptides, and their aggregates into the brain parenchyma. One of these potential toxins is the $A \beta$ peptide, which causes neurodegeneration, acute necrotic damage and long-lasting degenerative processes, that in turn will activate an inflammatory response.

Reactive microglia are closely associated with senile plaques in AD patients, and microglia can contain intracellular deposits of $A \beta$, which indicates a role for these cells in the clearance and/or processing of $A \beta$ (Mandrekar et al., 2009, Weldon et al., 1998). Heat sock proteins (HSP), which exhibit chaperone activity and are overexpressed following many injuries including AD and stroke (Turturici et al., 2011), induced microglial phagocytosis of A $\beta$ peptides, probably mediated through NF-kB and p38 MAPK pathways and TLR4. Certainly, a possible explanation for phagocytosis activation by microglia is that HSP70-associated peptides are more immunogenic for both MHC class I- and II-dependent systems than 
peptides alone (Mycko et al., 2004). On the other hand, senile plaque-associated microglia expressed significantly more MHC-II, IL-1, the receptor for macrophage-colony stimulating factor-1, myeloid cell-specific calcium-binding protein MRP14 and CD40, all of which are associated with mononuclear phagocyte activation and inflammation. In addition, CCR3 and CCR5 have also been found in microglia associated with AD plaques, whereas CXCR2 and CXCR3 have been associated with neuritic plaques (Hickman et al., 2008). The CX3CL1/CX3CR1 pathway plays a part in microglia neurotoxicity in vivo, but also participates in microglial phagocytosis of $A \beta$ and activation of the astroglial response (Lee et al., 2010). Interestingly, early microglial recruitment in AD promotes $A \beta$ clearance and is neuroprotective, whereas chronic proinflammatory cytokine production in response to $A \beta$ deposition downregulates genes involved in $A \beta$ clearance, promotes its accumulation, and contributes to neurodegeneration (Hickman et al., 2008). It is noteworthy that in AD patients the classic inflammatory response (immunoglobulin and leucocyte infiltration) is absent (Eikelenboom \& Veerhuis, 1996).

The generation of $A \beta$ is initiated by $\beta$-secretase cleavage of APP (also called $\beta$-site APP-cleaving enzyme, BACE1), which is mostly present in neurons (Vassar et al., 1999). Ischemia strengthens the expression and activity of BACE1 (Wen et al., 2004), and notably, the early post-hypoxic upregulation of BACE1 depends on the production of ROS mediated by the sudden interruption of the mitochondrial electron transport chain, while the later expression of BACE1 is caused by activation of hypoxia inducible factor 1-a (Guglielmotto et al., 2009). After stroke, the activation of caspase-3 induces the ubiquitin-dependent stabilization of BACE1 (Tesco et al., 2007), thereby seeding the formation of oligomeric and fibrillar amyloid structures.

On the other hand, the intramembrane proteases presenilin 1 (PS1) and preselinin 2 (PS2) are part of the $\gamma$-secretase catalytic site, which in conjunction with BACE1, processes APP to generate $A \beta$. After an ischemic event, the $\gamma$-secretase activity is increased at the boundary of the infarct (Arumugam et al., 2006). Mutations in the genes encoding PS1 and PS2 cause early-onset familial AD (Thinakaran \& Parent, 2004). In addition, mutant PSexpressing and PS-conditional knock out mice have shown aberrant neuroinflammatory response, which suggests a link between PS function and CNS innate immune response regulation (Beglopoulos et al., 2004). In this regard, TNF-a and IFNY production upregulates BACE1 (Yamamoto et al., 2007) and stimulates $\gamma$-secretase-mediated cleavage of APP (Liao et al., 2004). Thus, proinflammatory cytokines would also contribute to ADlike pathology by promoting A $\beta$ generation. Nonetheless, PS expression in microglial cells shows compensatory regulation where PS1 knockdown leads to increased PS2 and vice versa. But only PS2 depletion correlates with decreased $\gamma$-secretase function (Jayadev et al., 2010), and only PS2 might be implicated in A $\beta$ phagocytosis by microglial cells (Farfara et al., 2011).

\subsection{Chronic neuroinflammation}

Neuroinflammation is a common characteristic of the pathological process in neurodegenerative diseases such as PD, AD, ALS, and multiple sclerosis (Graeber \& Streit, 2010). Microgliosis is related to the molecular pathology of these diseases and has been associated with misfolded proteins, in the case of PD, ALS and Huntington's disease, where the misfolded proteins accumulate intracellularly, and with extracellular aggregates, as in the case of $A \beta$ in $A D$. Activation of the microglia is also associated with the formation of 
calcium precipitates of hydroxyapatites, which are frequently observed in the specific CNS areas involved in neurodegenerative processes (Rodriguez et al., 2009b).

The benefits of such inflammation are substantial. For example, in the early stages of AD, reactive microglia phagocytose and degrade $A \beta$ (Paresce et al., 1997), scavenges and eliminate the debris of dead or dying cells, and therefore protect the brain from its toxic effects (El Khoury et al., 2007) and the effects of other toxic agents released by dying cells (Figure 3). Furthermore, reactive astrocytes isolate neurons from senile plaques and release cytokines and growth factors that may help damaged neurons to survive and recover. However, when the disease progresses and a persistent proinflammatory cytokine production occurs, microglia release high amounts of TNF- $\alpha$ and IL-1 $\beta$, and therefore lose their protective phenotype and their ability to phagocytose $A \beta$ deposition. In these conditions, microglia become dysfunctional and fail to clear $\mathrm{A} \beta$ deposits (Hickman et al., 2008), hence promoting plaque formation (Bolmont et al., 2008). This chronic and uncontrolled inflammatory response can directly lead to the injury or death of neurons (Figure 3). In addition, activated microglia may also be directly involved in the generation of senile plaque pathology, either by the secretion of fibrilar and soluble $A \beta$ (Chung et al., 1999) or by the release of biometals such as iron, which aggregates soluble $A \beta$ fragments. For that reason, this innate immune response is currently considered a potential pathogenic factor for neurodegenerative diseases.

As explained above, microglia respond to tissue injury by adopting a diversity of phenotypes ranging from the deleterious M1 to the neuroprotective M2 (Halliday \& Stevens, 2011, Henkel et al., 2009). This range of phenotypes is closely related to the evolution of the lesion process and their control will directly influence the outcome of the tissue. In addition, some microglial cells become increasingly dysfunctional with age and may play a direct role in the development of neurodegeneration (Block et al., 2007, Stoll et al., 2002). Whether microglia adopt a phenotype that mostly exacerbates tissue injury or one that promotes brain repair is likely to depend on the diversity of signals from the lesion environment and the response capacity of the aging cell.

In a complex crosstalk that is being progressively deciphered, astrocytes and inflammatory T-cell subsets influence the proinflammatory or anti-inflammatory responses of microglia, thus affecting their antigen-presenting cell properties and phagocytic capacity. Astrocytes generate local signals, such as glutamate, to communicate with neurons and these signals influence the outcome of the tissue during neurodegeneration (Allaman et al., 2011). They directly influence microglial behaviour by playing a critical role in the activation of microglia under infectious conditions (Ovanesov et al., 2008) and in multiple sclerosis, where MCP-1/CCL2 and IP-10/CXCL10 direct reactive gliosis (Tanuma et al., 2006). Some findings have implicated astrocytes in chronic microgliosis. For example, TNF-a secretion is crucial for rapid autocrine microglial activation with both neuroprotective and cytotoxic effects, a process that is also fed by TNF-a released by reactive astrocytes (Suzumura et al., 2006). These opposing TNF- $\alpha$ actions depend on the activation of two specific receptors: TNFR1, which has a low affinity and an intracellular death domain, and TNFR2, which has a high affinity and is mainly involved in neuroprotection (Fontaine et al., 2002). Therefore, at low concentrations, TNF- $\alpha$ only binds to TNFR2 and potentiates neuronal survival, whereas the subsequent TNF- $\alpha$ secretion by microglia and astrocytes activates TNFR1 in neurons and astrocytes and contributes to cell injury (Bernardino et al., 2008). 


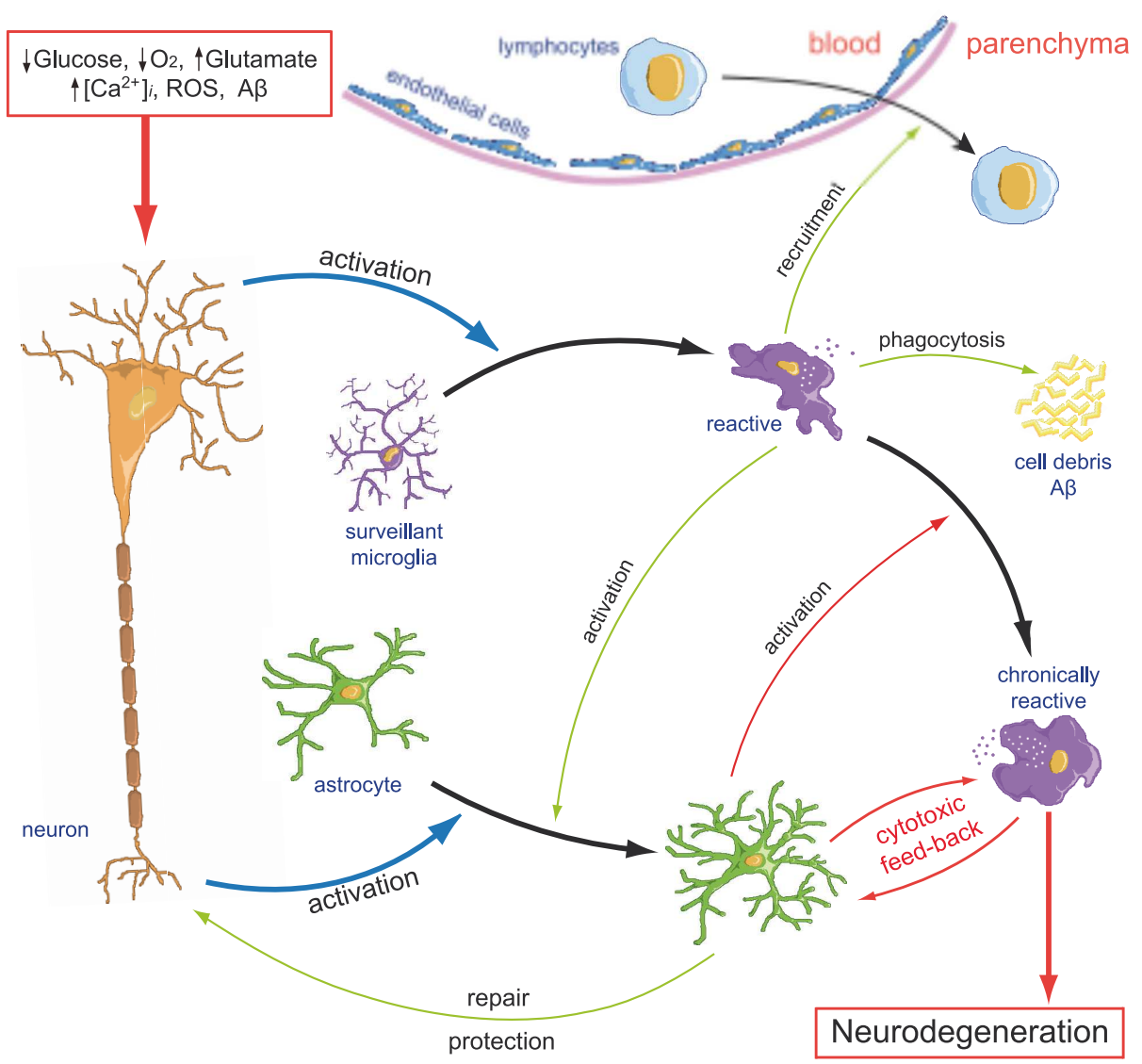

Fig. 3. Cellular processes involving chronic neuroinflammation after brain injury.

Physiological modifications (molecules inside a red square) alter neurons, which in turn release activation signals to astrocytes and microglia. Reactive microglia mediate different pro-inflammatory and neuroprotective processes (green arrows) in coordination with reactive astrocytes. With increasing activation signals or reaction times, reactive microglia become increasingly dysfunctional and adopt a chronic reactive phenotype mostly cytotoxic that directly participates of neurodegeneration. Astrocytes may also promote this microglia cytotoxic activity by releasing activation signals (red arrows)

Thus, chronic microgliosis after CNS injury and during neurodegeneration involves a putative transition from an initial neuroprotective activity to a cytotoxic activity, and the interaction of astrocytes in the lesion site that promote the cytotoxic microglial phenotype through the secretion of TNF- $a$ and other signals (Donato et al., 2009, Suzumura et al., 2006). In this scenario, the interplay between the trophic, neuroprotective, inflammatory and cytotoxic functions of microglia and astrocytes in acute and chronic CNS injury will determine the evolution of the neurodegenerative process. Control of this time-depending crosstalk requires a precise and dynamic analysis of the interactions so as to effectively develop approaches to neuroprotection and restoration of the injured tissue. 


\section{Conclusions}

CNS injuries such as stroke, traumatic brain injury and spinal cord injury, are characterized by the appearance of common parameters that determine the outcome of the tissue and account for the ensuing neurodegenerative process underlied by glutamate-mediated excitotoxicity, calcium dyshomeostasis and neuroinflammation. At the tissue level, the pathogenesis of each disorder depends primarily on the availability of energy but also on the neuronal type involved, the synaptic density, the glial interactions, and the vicinity of vascularization. These parameters also underlie the ensuing neurodegenerative process that will determine the dynamics and progression of the disease but also the success of regenerative therapies.

The literature suggests that several treatment interventions can promote the regeneration of damaged tissue after an acute injury. The degree of such regeneration remains modest, but the diversity of mechanisms that may promote tissue recovery increases the options for developing new therapies. Therefore, future therapeutic approaches should include dealing with excitotoxicity and energy production, and controlling neuroinflammatory pathways, as complementary treatments to those addressed to overcome the inhibitory mechanisms that block regeneration and to enhance neuronal plasticity.

\section{Acknowledgements}

This research was supported by grants SAF2008-01902 and IPT-010000-2010-35 from the Ministerio de Ciencia e Innovación, and by grant 2009SGR1380 from the Generalitat de Catalunya, Spain.

\section{References}

Allaman, I., Belanger, M. \& Magistretti, P.J. (2011). Astrocyte-neuron metabolic relationships: for better and for worse. Trends Neurosci, Vol. 34, No. 2, pp. 76-87, ISSN 1878-108X

Amantea, D., Nappi, G., Bernardi, G., Bagetta, G. \& Corasaniti, M.T. (2009). Post-ischemic brain damage: pathophysiology and role of inflammatory mediators. FEBS J, Vol. 276, No. 1, pp. 13-26, ISSN 1742-4658

Arumugam, T.V., Chan, S.L., Jo, D.G., Yilmaz, G., Tang, S.C., Cheng, A., Gleichmann, M., Okun, E., Dixit, V.D., Chigurupati, S., Mughal, M.R., Ouyang, X., Miele, L., Magnus, T., Poosala, S., Granger, D.N. \& Mattson, M.P. (2006). Gamma secretasemediated Notch signaling worsens brain damage and functional outcome in ischemic stroke. Nat Med, Vol. 12, No. 6, pp. 621-3, ISSN 1078-8956

Bailey, S.L., Carpentier, P.A., Mcmahon, E.J., Begolka, W.S. \& Miller, S.D. (2006). Innate and adaptive immune responses of the central nervous system. Crit Rev Immunol, Vol. 26, No. 2, pp. 149-88, ISSN 1040-8401

Bano, D., Young, K.W., Guerin, C.J., Lefeuvre, R., Rothwell, N.J., Naldini, L., Rizzuto, R., Carafoli, E. \& Nicotera, P. (2005). Cleavage of the plasma membrane $\mathrm{Na}^{+} / \mathrm{Ca}^{2+}$ exchanger in excitotoxicity. Cell, Vol. 120, No. 2, pp. 275-85, ISSN 0092-8674

Beal, M.F. (2000). Energetics in the pathogenesis of neurodegenerative diseases. Trends Neurosci, Vol. 23, No. 7, pp. 298-304, ISSN 0166-2236 
Beck, A., Nieden, R.Z., Scheinder, H.P. \& Deitmer, J.W. (2004). Calcium release from intracellular stores in rodent astrocytes and neurons in situ. Cell Calcium, Vol. 35 No. pp. 47-58, ISSN 0143-4160

Beglopoulos, V., Sun, X., Saura, C.A., Lemere, C.A., Kim, R.D. \& Shen, J. (2004). Reduced beta-amyloid production and increased inflammatory responses in presenilin conditional knock-out mice. J Biol Chem, Vol. 279, No. 45, pp. 46907-14, ISSN 00219258

Bernal, F., Saura, J., Ojuel, J. \& Mahy, N. (2000). Differential vulnerability of hippocampus, basal ganglia and prefrontal cortex to long-term NMDA excitotoxicity. Exp Neurol, Vol. 161, No. pp. 686-695, ISSN 0014-4886

Bernardino, L., Agasse, F., Silva, B., Ferreira, R., Grade, S. \& Malva, J.O. (2008). Tumor necrosis factor-alpha modulates survival, proliferation, and neuronal differentiation in neonatal subventricular zone cell cultures. Stem Cells, Vol. 26, No. 9, pp. 2361-2371, ISSN 1066-5099

Berridge, M.J. (1998). Neuronal calcium signaling. Neuron, Vol. 21, No. pp. 13-26, ISSN 08966273

Bessis, A., Bechade, C., Bernard, D. \& Roumier, A. (2007). Microglial control of neuronal death and synaptic properties. Glia, Vol. 55, No. 3, pp. 233-8, ISSN 0894-1491

Block, M.L., Zecca, L. \& Hong, J.S. (2007). Microglia-mediated neurotoxicity: uncovering the molecular mechanisms. Nat.Rev.Neurosci., Vol. 8, No. pp. 57-69, ISSN 1471-003X

Bolmont, T., Haiss, F., Eicke, D., Radde, R., Mathis, C.A., Klunk, W.E., Kohsaka, S., Jucker, M. \& Calhoun, M.E. (2008). Dynamics of the microglial/amyloid interaction indicate a role in plaque maintenance. J Neurosci, Vol. 28, No. 16, pp. 4283-92, ISSN 1529-2401

Camandola S \& Mattson MP. (2011) Aberrant subcellular neuronal calcium regulation in aging and Alzheimer's disease. Biochim Biophys Acta, Vol 1813, pp. 965-973, ISSN 0005-2728

Carson, M.J., Thrash, J.C. \& Walter, B. (2006). The cellular response in neuroinflammation: The role of leukocytes, microglia and astrocytes in neuronal death and survival. Clin Neurosci Res, Vol. 6, No. 5, pp. 237-245, ISSN 1566-2772

Carulla, N., Caddy, G.L., Hall, D.R., Zurdo, J., Gairi, M., Feliz, M., Giralt, E., Robinson, C.V. \& Dobson, C.M. (2005). Molecular recycling within amyloid fibrils. Nature, Vol. 436, No. 7050, pp. 554-8, ISSN 1476-4687

Carulla, N., Zhou, M., Giralt, E., Robinson, C.V. \& Dobson, C.M. (2010). Structure and intermolecular dynamics of aggregates populated during amyloid fibril formation studied by hydrogen/deuterium exchange. Acc Chem Res, Vol. 43, No. 8, pp. 1072-9, ISSN 1520-4898

Chan, S.L., Liu, D., Kyriazis, G.A., Bagsiyao, P., Ouyang, X. \& Mattson, M.P. (2006). Mitochondrial uncoupling protein-4 regulates calcium homeostasis and sensitivity to store-depletion-induced apoptosis in neural cells. J Biol Chem, Vol. 281 No. 49 pp.37391-37403, ISSN 0021-9258

Chen, Q., Olney, J.W., Lukasiewicz, P.D., Almli, T. \& Romano, C. (1998). Ca ${ }^{2+}$-independent excitotoxic neurodegeneration in isolated retina, an intact neural net: a role for $\mathrm{Cl}^{-}$ and inhibitory transmitters. Mol Pharmacol, Vol. 53, No. 3, pp. 564-572, ISSN 0026895X 
Chung, H., Brazil, M.I., Soe, T.T. \& Maxfield, F.R. (1999). Uptake, degradation, and release of fibrillar and soluble forms of Alzheimer's amyloid beta-peptide by microglial cells. J Biol Chem, Vol. 274, No. 45, pp. 32301-8, ISSN 0021-9258

De La Torre, J.C. (2008). Alzheimer's disease prevalence can be lowered with non-invasive testing. J Alzheimers Dis, Vol. 14, No. 3, pp. 353-9, ISSN 1387-2877

Deane, R., Du Yan, S., Submamaryan, R.K., Larue, B., Jovanovic, S., Hogg, E., Welch, D., Manness, L., Lin, C., Yu, J., Zhu, H., Ghiso, J., Frangione, B., Stern, A., Schmidt, A.M., Armstrong, D.L., Arnold, B., Liliensiek, B., Nawroth, P., Hofman, F., Kindy, M., Stern, D. \& Zlokovic, B. (2003). RAGE mediates amyloid-beta peptide transport across the blood-brain barrier and accumulation in brain. Nat Med, Vol. 9, No. 7, pp. 907-13, ISSN 1078-8956

Deane, R., Wu, Z. \& Zlokovic, B.V. (2004). RAGE (yin) versus LRP (yang) balance regulates alzheimer amyloid beta-peptide clearance through transport across the blood-brain barrier. Stroke, Vol. 35, No. 11 Suppl 1, pp. 2628-31, ISSN 1524-4628

Dirscherl, K., Karlstetter, M., Ebert, S., Kraus, D., Hlawatsch, J., Walczak, Y., Moehle, C., Fuchshofer, R. \& Langmann, T. (2010). Luteolin triggers global changes in the microglial transcriptome leading to a unique anti-inflammatory and neuroprotective phenotype. J Neuroinflammation, Vol. 7, No. 3, pp. 3, ISSN 17422094

Donato, R., Sorci, G., Riuzzi, F., Arcuri, C., Bianchi, R., Brozzi, F., Tubaro, C. \& Giambanco, I. (2009). S100B's double life: intracellular regulator and extracellular signal. Biochim Biophys Acta, Vol. 1793, No. 6, pp. 1008-1022, ISSN 0304-4165

Drew, S.C., Masters, C.L. \& Barnham, K.J. (2010). Alzheimer's Abeta peptides with diseaseassociated N-terminal modifications: influence of isomerisation, truncation and mutation on Cu2+ coordination. PLoS One, Vol. 5, No. 12, pp. e15875, ISSN 19326203

Drzezga, A., Lautenschlager, N., Siebner, H., Riemenschneider, M., Willoch, F., Minoshima, S., Schwaiger, M. \& Kurz, A. (2003). Cerebral metabolic changes accompanying conversion of mild cognitive impairment into Alzheimer's disease: a PET follow-up study. Eur J Nucl Med Mol Imaging, Vol. 30, No. 8, pp. 1104-13, ISSN 1619-7070

Eikelenboom, P. \& Veerhuis, R. (1996). The role of complement and activated microglia in the pathogenesis of Alzheimer's disease. Neurobiol Aging, Vol. 17, No. 5, pp. 673-80, ISSN 0197-4580

Ekdahl, C.T., Kokaia, Z. \& Lindvall, O. (2009). Brain inflammation and adult neurogenesis: the dual role of microglia. Neuroscience, Vol. 158, No. 3, pp. 1021-1029, ISSN 03064522

El Khoury, J., Toft, M., Hickman, S.E., Means, T.K., Terada, K., Geula, C. \& Luster, A.D. (2007). Ccr2 deficiency impairs microglial accumulation and accelerates progression of Alzheimer-like disease. Nat Med, Vol. 13, No. 4, pp. 432-8, ISSN 1078-8956

Farfara, D., Trudler, D., Segev-Amzaleg, N., Galron, R., Stein, R. \& Frenkel, D. (2011). gamma-Secretase component presenilin is important for microglia beta-amyloid clearance. Ann Neurol, Vol. 69, No. 1, pp. 170-80, 1531-8249

Fontaine, V., Mohand-Said, S., Hanoteau, N., Fuchs, C., Pfizenmaier, K. \& Eisel, U. (2002). Neurodegenerative and neuroprotective effects of tumor Necrosis factor (TNF) in 
retinal ischemia: opposite roles of TNF receptor 1 and TNF receptor 2. J Neurosci, Vol. 22, No. 7, pp. RC216, ISSN 1529-2401

Forman, M.S., Trojanowski, J.Q. \& Lee, V.M. (2004). Neurodegenerative diseases: a decade of discoveries paves the way for therapeutic breakthroughs. Nat Med, Vol. 10, No. 10, pp. 1055-63, ISSN 1078-8956

Frijns, C.J. \& Kappelle, L.J. (2002). Inflammatory cell adhesion molecules in ischemic cerebrovascular disease. Stroke, Vol. 33, No. 8, pp. 2115-22, ISSN 1524-4628

Fukuda, S., Fini, C.A., Mabuchi, T., Koziol, J.A., Eggleston, L.L., Jr. \& Del Zoppo, G.J. (2004). Focal cerebral ischemia induces active proteases that degrade microvascular matrix. Stroke, Vol. 35, No. 4, pp. 998-1004, ISSN 1524-4628

Gadad, B.S., Britton, G.B. \& Rao, K.S. (2011). Targeting oligomers in neurodegenerative disorders: lessons from alpha-synuclein, tau, and amyloid-beta peptide. J Alzheimers Dis, Vol. 24 Suppl 2, No. pp. 223-32, ISSN 1875-8908

Gitler, A.D., Shorter, J. (2011) RNA-binding proteins with prion-like domains in ALS and FTLD-U. Prion, Vol 1, No. 3, pp. 5 ISSN 1933-690X

Graeber, M.B. \& Streit, W.J. (2010). Microglia: biology and pathology. Acta Neuropathol, Vol. 119, No. 1, pp. 89-105, ISSN 1432-0533

Guglielmotto, M., Aragno, M., Autelli, R., Giliberto, L., Novo, E., Colombatto, S., Danni, O., Parola, M., Smith, M.A., Perry, G., Tamagno, E. \& Tabaton, M. (2009). The upregulation of BACE1 mediated by hypoxia and ischemic injury: role of oxidative stress and HIF1alpha. J Neurochem, Vol. 108, No. 4, pp. 1045-56, ISSN 0022-3042

Haces, M.L., Montiel, T. \& Massieu, L. (2010). Selective vulnerability of brain regions to oxidative stress in a non-coma model of insulin-induced hypoglycemia. Neuroscience, Vol. 165, No. 1, pp. 28-38, ISSN 0306-4522

Halliday, G.M. \& Stevens, C.H. (2011). Glia: initiators and progressors of pathology in Parkinson's disease. Mov Disord, Vol. 26, No. 1, pp. 6-17, ISSN 0885-3185

Henkel, J.S., Beers, D.R., Zhao, W. \& Appel, S.H. (2009). Microglia in ALS: the good, the bad, and the resting. J Neuroimmune Pharmacol, Vol. 4, No. 4, pp. 389-98, ISSN 1557-1904

Hickman, S.E., Allison, E.K. \& El Khoury, J. (2008). Microglial dysfunction and defective beta-amyloid clearance pathways in aging Alzheimer's disease mice. J Neurosci, Vol. 28, No. 33, pp. 8354-60, ISSN 10270-6474

Higuchi, K., Matsumura, A., Honma, A., Takeshita, S., Hashimoto, K., Hosokawa, M., Yasuhira, K., Takeda, T. (1983) Systemic senile amyloid in senescence-accelerated mice. A unique fibril protein demonstrated in tissues from various organs by the unlabeled immunoperoxidase method. Lab Invest, Vol. 48 No. 2 pp. 231-240. ISSN 0023-6837

Jayadev, S., Case, A., Eastman, A.J., Nguyen, H., Pollak, J., Wiley, J.C., Moller, T., Morrison, R.S. \& Garden, G.A. (2010). Presenilin 2 is the predominant gamma-secretase in microglia and modulates cytokine release. PLoS One, Vol. 5, No. 12, pp. e15743, ISSN 1932-6203

Johnson, N.A., Jahng, G.H., Weiner, M.W., Miller, B.L., Chui, H.C., Jagust, W.J., GornoTempini, M.L. \& Schuff, N. (2005). Pattern of cerebral hypoperfusion in Alzheimer disease and mild cognitive impairment measured with arterial spin-labeling MR imaging: initial experience. Radiology, Vol. 234, No. 3, pp. 851-9, ISSN 0033-8419

Kaku, D.A., Giffard, R.G. \& Choi, D.W. (1993). Neuroprotective effects of glutamate antagonists and extracellular acidity. Science, Vol. 260, No. pp. 1516-1518, 
Katayama, Y., Maeda, T., Koshinaga, M., Kawamata, T. \& Tsubokawa, T. (1995). Role of excitatory amino acid-mediated ionic fluxes in traumatic brain injury. Brain Pathol, Vol. 5, No. pp. 427-435, ISSN 1750-3639

Keller, J.N., Pang, Z., Geddes, J.W., Begley, J.G., Germeyer, A., Waeg, G. \& Mattson, M.P. (1997). Impairment of glucose and glutamate transport and induction of mitochondrial oxidative stress and dysfunction in synaptosomes by amyloid betapeptide: role of the lipid peroxidation product 4-hydroxynonenal. J Neurochem, Vol. 69, No. 1, pp. 273-84, ISSN 0022-3042

Kettenmann, H., Hanisch, U.K., Noda, M. \& Verkhratsky, A. (2011). Physiology of microglia. Physiol Rev, Vol. 91, No. 2, pp. 461-553, ISSN 1522-1210

Koistinaho, M. \& Koistinaho, J. (2005). Interactions between Alzheimer's disease and cerebral ischemia-focus on inflammation. Brain Res Brain Res Rev, Vol. 48 No. pp. 240-250, ISSN 0165-0173

Lau, A. \& Tymianski, M. (2010). Glutamate receptors, neurotoxicity and neurodegeneration. Pflugers Arch, Vol. 460, No. 2, pp. 525-42, ISSN 1432-2013

Le Jeune, H., Cçcyre, D., Rowe, W., Meaney, M.J. \& Quirion, R. (1996). Ionotropic glutamate receptor subtypes in the aged memory-impaired and unimpaired Long-Evans rat. Neuroscience, Vol. 74, No. 2, pp. 349-363, ISSN 0306-4522

Lebon, V., Petersen, K.F., Cline, G.W., Shen, J., Mason, G.F., Dufour, S., Behar, K.L., Shulman, G.I. \& Rothman, D.L. (2002). Astroglial contribution to brain energy metabolism in humans revealed by ${ }^{13} \mathrm{C}$ nuclear magnetic resonance spectroscopy: elucidation of the dominant pathway for neurotransmitter glutamate repletion and measurement of astrocytic oxidative metabolism. J Neurosci, Vol. 22, No. 5, pp. 1523-1531, ISSN 0270-6474

Lee, S., Varvel, N.H., Konerth, M.E., Xu, G., Cardona, A.E., Ransohoff, R.M. \& Lamb, B.T. (2010). CX3CR1 deficiency alters microglial activation and reduces beta-amyloid deposition in two Alzheimer's disease mouse models. Am J Pathol, Vol. 177, No. 5, pp. 2549-62, ISSN 1525-2191

Liang, B., Duan, B.Y., Zhou, X.P., Gong, J.X. \& Luo, Z.G. (2010). Calpain activation promotes BACE1 expression, amyloid precursor protein processing, and amyloid plaque formation in a transgenic mouse model of Alzheimer disease. J Biol Chem, Vol. 285, No. 36, pp. 27737-44, ISSN 1083-351X

Liao, Y.F., Wang, B.J., Cheng, H.T., Kuo, L.H. \& Wolfe, M.S. (2004). Tumor necrosis factoralpha, interleukin-1beta, and interferon-gamma stimulate gamma-secretasemediated cleavage of amyloid precursor protein through a JNK-dependent MAPK pathway. J Biol Chem, Vol. 279, No. 47, pp. 49523-32, ISSN 0021-9258

Mandrekar, S., Jiang, Q., Lee, C.Y., Koenigsknecht-Talboo, J., Holtzman, D.M. \& Landreth, G.E. (2009). Microglia mediate the clearance of soluble Abeta through fluid phase macropinocytosis. J Neurosci, Vol. 29, No. 13, pp. 4252-4262, ISSN 0270-6474

Mantovani, A., Sica, A., Sozzani, S., Allavena, P., Vecchi, A. \& Locati, M. (2004). The chemokine system in diverse forms of macrophage activation and polarization. Trends Immunol, Vol. 25, No. 12, pp. 677-86, ISSN 1471-4906

Mark, R.J., Lovell, M.A., Markesbery, W.R., Uchida, K. \& Mattson, M.P. (1997). A role for 4hydroxynonenal, an aldehydic product of lipid peroxidation, in disruption of ion homeostasis and neuronal death induced by amyloid beta-peptide. J Neurochem, Vol. 68, No. 1, pp. 255-64, ISSN 0022-3042 
Mattson, M.P. (1990). Antigenic changes similar to those seen in neurofibrillary tangles are elicited by glutamate and $\mathrm{Ca}^{2+}$ influx in cultured hippocampal neurons. Neuron, Vol. 2, No. pp. 105-117, ISSN 0896-6273

Mattson, M.P. (2006). Neuronal life-and-death signaling, apoptosis, and neurodegenerative disorders. Antioxid Redox Signal., Vol. 8, No. 11-12, pp. 1997-2006, ISSN 1557-7716

Miele, V.J., Bailes, J.E., Cantu, R.C. \& Rabb, C.H. (2006). Subdural hematomas in boxing: the spectrum of consequences. Neurosurgery Focus, Vol. 21 No. pp. E10, ISSN 1092-0684

Morales, R., Estrada, L.D., Diaz-Espinoza, R., Morales-Scheihing, D., Jara, M.C., Castilla, J. \& Soto, C. (2010). Molecular cross talk between misfolded proteins in animal models of Alzheimer's and prion diseases. J Neurosci, Vol. 30, No. 13, pp. 4528-35, ISSN 1529-2401

Mycko, M.P., Cwiklinska, H., Szymanski, J., Szymanska, B., Kudla, G., Kilianek, L., Odyniec, A., Brosnan, C.F. \& Selmaj, K.W. (2004). Inducible heat shock protein 70 promotes myelin autoantigen presentation by the HLA class II. J Immunol, Vol. 172, No. 1, pp. 202-13, ISSN 0022-1767

Neumann, H., Boucraut, J., Hahnel, C., Misgeld, T. \& Wekerle, H. (1996). Neuronal control of MHC class II inducibility in rat astrocytes and microglia. Eur J Neurosci, Vol. 8, No. 12, pp. 2582-90, ISSN 0953-816X

Nicholls, D.G., Vesce, S., Kirk, L. \& Chalmers, S. (2003). Interactions between mitochondrial bioenergetics and cytoplasmic calcium in cultured cerebellar granule cells. Cell Calcium, Vol. 34 No. pp. 407-424, ISSN 0143-4160

Nicotera, P., Leist, M. \& Manzo, L. (1999). Neuronal cell death: a demise with different shapes. Trends Pharmacol Sci, Vol. 20, No. pp. 46-51, ISSN 0165-6147

Obrenovitch, T.P., Urenjak, J., Zilkha, E. \& Jay, T.M. (2000). Excitotoxicity in neurological disorders--the glutamate paradox. Int J Dev Neurosci, Vol. 18, No. 2-3, pp. 281-287, ISSN 0736-5748

Olney, J.W., Wozniak, D.F. \& Farber, N.B. (1997). Excitotoxic neurodegeneration in Alzheimer disease. Arch Neurol, Vol. 54, No. pp. 1234-1240, ISSN 0003-9942

Orrenius, S., Zhivotovsky, B. \& Nicotera, P. (2003). Regulation of cell death: the calciumapoptosis link. Nat Rev Mol Cell Biol., Vol. 4, No. 7, pp. 552-565, ISSN 1471-0072

Ovanesov, M.V., Ayhan, Y., Wolbert, C., Moldovan, K., Sauder, C. \& Pletnikov, M.V. (2008). Astrocytes play a key role in activation of microglia by persistent Borna disease virus infection. J Neuroinflammation, Vol. 5, No. pp. 50, ISSN 1742-2094

Paresce, D.M., Chung, H. \& Maxfield, F.R. (1997). Slow degradation of aggregates of the Alzheimer's disease amyloid beta-protein by microglial cells. J Biol Chem, Vol. 272, No. 46, pp. 29390-7, ISSN 0021-9258

Petegnief, V., Ursu, G., Bernal, F. \& Mahy, N. (2004). Nimodipine and TMB-8 potentiate the AMPA-induced lesion in the basal ganglia. Neurochem Int, Vol. 44 No. pp. 287-291, ISSN 0197-0186

Pluta, R. (2004). Alzheimer lesions after ischemia-reperfusion brain injury. Folia Neuropathol, Vol. 42 No. pp. 181-186, ISSN 0028-3894

Ramonet, D., De Yebra, L., Fredriksson, K., Bernal, F., Ribalta, T. \& Mahy, N. (2006). Similar calcification process in acute and chronic human brain pathologies. J Neurosci Res, Vol. 83 No. pp. 147-156, ISSN 1097-4547 
Ramonet, D., Pugliese, M., Rodríguez, M.J., De Yebra, L., Andrade, C., Adroer, R., Ribalta, T., Mascort, J. \& Mahy, N. (2002). Calcium precipitation in acute and chronic brain diseases. J Physiol-Paris, Vol. 96, No. pp. 307-312, ISSN 0928-4257

Ramonet, D., Rodríguez, M.J., Fredriksson, K., Bernal, F. \& Mahy, N. (2004). In vivo neuroprotective adaptation of the glutamate/glutamine cycle to neuronal death. Hippocampus, Vol. 14, No. 5, pp. 586-594, ISSN 1098-1063

Randall, R.D. \& Thayer, S.A. (1992). Glutamate-induced calcium transient triggers delayed calcium overload and neurotoxicity in rat hippocampal neurons. J Neurosci, Vol. 12, No. 5, pp. 1882-95, ISSN 0270-6474

Rodriguez, M.J., Bernal, F., Andres, N., Malpesa, Y. \& Mahy, N. (2000). Excitatory amino acids and neurodegeneration: a hypothetical role of calcium precipitation. Int J Dev Neurosci, Vol. 18, No. 2-3, pp. 299-307,

Rodriguez, M.J., Martinez-Sanchez, M., Bernal, F. \& Mahy, N. (2004). Heterogeneity between hippocampal and septal astroglia as a contributing factor to differential in vivo AMPA excitotoxicity. J Neurosci Res, Vol. 77, No. 3, pp. 344-353, ISSN 0736-5748

Rodriguez, M.J., Prats, A., Malpesa, Y., Andres, N., Pugliese, M., Batlle, M. \& Mahy, N. (2009a). Pattern of injury with a graded excitotoxic insult and ensuing chronic medial septal damage in the rat brain. J Neurotrauma, Vol. 26, No. 10, pp. 1823-34, ISSN 1557-9042

Rodriguez, M.J., Pugliese, M. \& Mahy, N. (2009b). Drug abuse, brain calcification and glutamate-induced neurodegeneration. Curr Drug Abuse Rev, Vol. 2, No. 1, pp. 99112, ISSN 1874-4745

Rodriguez, M.J., Robledo, P., Andrade, C. \& Mahy, N. (2005). In vivo co-ordinated interactions between inhibitory systems to control glutamate-mediated hippocampal excitability. J Neurochem, Vol. 95, No. 3, pp. 651-661, ISSN 0022-3042

Rodríguez, M.J., Ursu, G., Bernal, F., Cusí, V. \& Mahy, N. (2001). Perinatal human hypoxiaischemia vulnerability correlates with brain calcification. Neurobiol Dis, Vol. 8, No. pp. 59-68, ISSN 0969-9961

Rolls, A., Shechter, R., London, A., Ziv, Y., Ronen, A., Levy, R. \& Schwartz, M. (2007). Tolllike receptors modulate adult hippocampal neurogenesis. Nat Cell Biol, Vol. 9, No. 9, pp. 1081-8, ISSN 1465-7392

Rombouts, S. \& Scheltens, P. (2005). Functional connectivity in elderly controls and AD patients using resting state fMRI: a pilot study. Curr Alzheimer Res, Vol. 2, No. 2, pp. 115-6, ISSN 1567-2050

Saido, T.C. \& Iwata, N. (2006). Metabolism of amyloid beta peptide and pathogenesis of Alzheimer's disease. Towards presymptomatic diagnosis, prevention and therapy. Neurosci Res, Vol. 54, No. 4, pp. 235-53, ISSN 0168-0102

Sanchez, L., Madurga, S., Pukala, T., Vilaseca, M., Lopez-Iglesias, C., Robinson, C.V., Giralt, E. \& Carulla, N. (2011). Abeta40 and Abeta42 amyloid fibrils exhibit distinct molecular recycling properties. J Am Chem Soc, Vol. 133, No. 17, pp. 6505-8, ISSN $1520-5126$

Sapolsky, R.M. (2001). Cellular defenses against excitotoxic insults. J Neurochem, Vol. 76, No. pp. 1601-1611, ISSN 0022-3042

Schwartz, M., Butovsky, O., Bråck, W. \& Hanisch, U.K. (2006). Microglial phenotype: is the commitment reversible? Trends Neurosci, Vol. 29 No. 2, pp. 68-74, ISSN 0166-2236 
Sibson, N.R., Dhankhar, A., Mason, G.F., Rothman, D.L., Behar, K.L. \& Shulman, R.G. (1998). Stoichiometric coupling of brain glucose metabolism and glutamatergic neuronal activity. Proc Nat Acad Sci USA, Vol. 95, No. pp. 316-321, ISSN 0027-8424

Sica, A., Schioppa, T., Mantovani, A. \& Allavena, P. (2006). Tumour-associated macrophages are a distinct M2 polarised population promoting tumour progression: potential targets of anti-cancer therapy. Eur J Cancer, Vol. 42, No. 6, pp. 717-27, ISSN 09598049

Sierra, A., Encinas, J.M., Deudero, J.J., Chancey, J.H., Enikolopov, G., Overstreet-Wadiche, L.S., Tsirka, S.E. \& Maletic-Savatic, M. (2010). Microglia shape adult hippocampal neurogenesis through apoptosis-coupled phagocytosis. Cell Stem Cell, Vol. 7, No. 4, pp. 483-95, ISSN 1875-9777

Smith, D.H., Chen, X.H., Iwata, A. \& Graham, D.I. (2003). Amyloid beta accumulation in axons after traumatic brain injury in humans. J Neurosurg, Vol. 98, No. 5, pp. 1072-7, ISSN 0022-3085

Soto, C., Estrada, L. \& Castilla, J. (2006). Amyloids, prions and the inherent infectious nature of misfolded protein aggregates. Trends Biochem Sci, Vol. 31, No. 3, pp. 150-5, ISSN 0968-0004

Soulet, D. \& Rivest, S. (2008). Bone-marrow-derived microglia: myth or reality? Curr Opin Pharmacol, Vol. 8, No. 4, pp. 508-18, ISSN 1471-4892

Stoll, G., Jander, S. \& Schroeter, M. (2002). Detrimental and beneficial effects of injuryinduced inflammation and cytokine expression in the nervous system. Adv Exp Med Biol, Vol. 513, No. pp. 87-113, ISSN 0065-2598

Streit, W.J. (2005). Microglia and neuroprotection: implications for Alzheimer's disease. Brain Res Brain Res Rev, Vol. 48, No. 2, pp. 234-9, ISSN 0165-0173

Suzumura, A., Takeuchi, H., Zhang, G., Kuno, R. \& Mizuno, T. (2006). Roles of glia-derived cytokines on neuronal degeneration and regeneration. Ann N Y Acad Sci, Vol. 1088, No. pp. 219-29, ISSN 0077-8923

Tanuma, N., Sakuma, H., Sasaki, A. \& Matsumoto, Y. (2006). Chemokine expression by astrocytes plays a role in microglia/macrophage activation and subsequent neurodegeneration in secondary progressive multiple sclerosis. Acta Neuropathol, Vol. 112, No. 2, pp. 195-204, ISSN 0001-6322

Taylor, J.P., Hardy, J. \& Fischbeck, K.H. (2002). Toxic proteins in neurodegenerative disease. Science, Vol. 296, No. 5575, pp. 1991-5, ISSN 1095-9203

Tesco, G., Koh, Y.H., Kang, E.L., Cameron, A.N., Das, S., Sena-Esteves, M., Hiltunen, M., Yang, S.H., Zhong, Z., Shen, Y., Simpkins, J.W. \& Tanzi, R.E. (2007). Depletion of GGA3 stabilizes BACE and enhances beta-secretase activity. Neuron, Vol. 54, No. 5, pp. 721-37, ISSN 0896-6273

Thinakaran, G. \& Parent, A.T. (2004). Identification of the role of presenilins beyond Alzheimer's disease. Pharmacol Res, Vol. 50, No. 4, pp. 411-8, ISSN 1043-6618

Turturici, G., Sconzo, G. \& Geraci, F. (2011). Hsp70 and its molecular role in nervous system diseases. Biochem Res Int, Vol. 2011, No. pp. 618127, ISSN 2090-2255

Tymianski, M. \& Tator, C.H. (1996). Normal and abnormal calcium homeostasis in neurons: a basis for the pathophysiology of traumatic and ischemic central nervous system injury. Neurosurgery, Vol. 38, No. 6, pp. 1176-1195, ISSN 0898-4921

Tymianski, M., Wallace, M.C., Spigelman, I., Uno, M., Carlen, P.L., Tator, C.H. \& Charlton, M.P. (1993). Cell-permeant $\mathrm{Ca}^{2+}$ chelators reduce early excitotoxic and ischemic 
neuronal injury in vitro and in vivo. Neuron, Vol. 11, No. pp. 221-235, ISSN 08966273

Vassar, R., Bennett, B.D., Babu-Khan, S., Kahn, S., Mendiaz, E.A., Denis, P., Teplow, D.B., Ross, S., Amarante, P., Loeloff, R., Luo, Y., Fisher, S., Fuller, J., Edenson, S., Lile, J., Jarosinski, M.A., Biere, A.L., Curran, E., Burgess, T., Louis, J.C., Collins, F., Treanor, J., Rogers, G. \& Citron, M. (1999). Beta-secretase cleavage of Alzheimer's amyloid precursor protein by the transmembrane aspartic protease BACE. Science, Vol. 286, No. 5440, pp. 735-741, ISSN 1095-9203

Verkhratsky, A. (2007). Calcium and cell death. Subcell.Biochem., Vol. 45, No. pp. 465-480, ISSN 0306-0225

Vosler, P.S., Graham, S.H., Wechsler, L.R. \& Chen, J. (2009). Mitochondrial targets for stroke: focusing basic science research toward development of clinically translatable therapeutics. Stroke, Vol. 40, No. 9, pp. 3149-55, ISSN 1524-4628

Waite, J., Chen, A., Wardlow, M. \& Thal, L. (1994). Behavioural and biochemical consequences of combined lesions of the medial septum/diagonal band and nucleus basalis in the rat when ibotenic acid, quisqualic acid and AMPA are used. Exp Neurol, Vol. 30, No. pp. 214-229, ISSN 0014-4886

Wake, H., Moorhouse, A.J., Jinno, S., Kohsaka, S. \& Nabekura, J. (2009). Resting microglia directly monitor the functional state of synapses in vivo and determine the fate of ischemic terminals. J Neurosci, Vol. 29, No. 13, pp. 3974-80, ISSN 1529-2401

Weldon, D.T., Rogers, S.D., Ghilardi, J.R., Finke, M.P., Cleary, J.P., O'hare, E., Esler, W.P., Maggio, J.E. \& Mantyh, P.W. (1998). Fibrillar beta-amyloid induces microglial phagocytosis, expression of inducible nitric oxide synthase, and loss of a select population of neurons in the rat CNS in vivo. J Neurosci, Vol. 18, No. 6, pp. 21612173, ISSN 1529-2401

Wen, Y., Onyewuchi, O., Yang, S., Liu, R. \& Simpkins, J.W. (2004). Increased beta-secretase activity and expression in rats following transient cerebral ischemia. Brain Res, Vol. 1009, No. 1-2, pp. 1-8, ISSN 0006-8993

Werth, J.L. \& Thayer, S.A. (1994). Mitochondria buffer physiological calcium loads in cultured rat dorsal root ganglion neurons. J Neurosci, Vol. 14, No. pp. 348-356, ISSN 1529-2401

Westermark, P., Johnson, K.H., Pitkänen, P. (1985) Systemic amyloidosis: a review with emphasis on pathogenesis. Appl Pathol, Vol. 3 No. 1-2 pp. 55-68. ISSN 0252-1172

Yamamoto, M., Kiyota, T., Horiba, M., Buescher, J.L., Walsh, S.M., Gendelman, H.E. \& Ikezu, T. (2007). Interferon-gamma and tumor necrosis factor-alpha regulate amyloid-beta plaque deposition and beta-secretase expression in Swedish mutant APP transgenic mice. Am J Pathol, Vol. 170, No. 2, pp. 680-92, ISSN 0002-9440

Zlokovic, B.V. (2005). Neurovascular mechanisms of Alzheimer's neurodegeneration. Trend Neurosci, Vol. 28 No. pp. 202-208, ISSN 0166-2236 


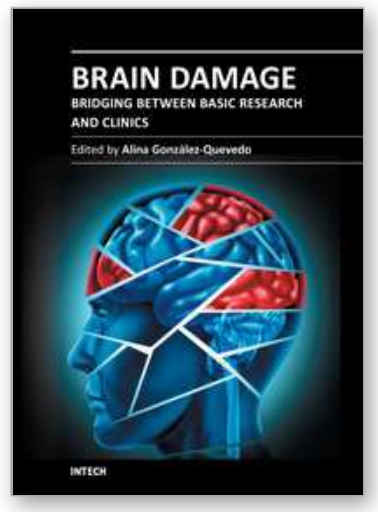

\author{
Brain Damage - Bridging Between Basic Research and Clinics \\ Edited by Dr. Alina Gonzalez-Quevedo
}

ISBN 978-953-51-0375-2

Hard cover, 282 pages

Publisher InTech

Published online 16, March, 2012

Published in print edition March, 2012

"Brain Damage - Bridging Between Basic Research and Clinics" represents a collection of papers in an attempt to provide an up-to-date approach to the fascinating topic of brain damage in different pathological situations, combining the authors' personal experiences with current knowledge in this field. In general, the necessary link between basic and clinical neurosciences is highlighted, as it is through this interaction that the theoretical understanding of the pathophysiological mechanisms can be successfully translated into better ways to diagnose, treat and prevent the catastrophic events that occur when the brain suffers from external or internal noxious events. The book spans different aspects of brain injury, starting from damage occurring in the fetal and child brain, followed by different neurodegenerative processes. Attention is also focused on the negative effects of drug addictions and sleep deprivation on the brain, as well as on the early assessment of brain injury for preventive strategies employing sensitive biomarkers.

\title{
How to reference
}

In order to correctly reference this scholarly work, feel free to copy and paste the following:

Francisco J. Ortega, Jose M. Vidal-Taboada, Nicole Mahy and Manuel J. Rodríguez (2012). Molecular Mechanisms of Acute Brain Injury and Ensuing Neurodegeneration, Brain Damage - Bridging Between Basic Research and Clinics, Dr. Alina Gonzalez-Quevedo (Ed.), ISBN: 978-953-51-0375-2, InTech, Available from: $\mathrm{http}: / /$ www.intechopen.com/books/brain-damage-bridging-between-basic-research-and-clinics/molecularmechanisms-of-acute-brain-injury-and-ensuing-neurodegeneration

\section{INTECH}

open science | open minds

\section{InTech Europe}

University Campus STeP Ri

Slavka Krautzeka 83/A

51000 Rijeka, Croatia

Phone: +385 (51) 770447

Fax: +385 (51) 686166

www.intechopen.com

\section{InTech China}

Unit 405, Office Block, Hotel Equatorial Shanghai

No.65, Yan An Road (West), Shanghai, 200040, China

中国上海市延安西路65号上海国际贵都大饭店办公楼405单元

Phone: +86-21-62489820

Fax: $+86-21-62489821$ 